\title{
ALIEN SPECIES INVASION AND DIVERSITY OF RIPARIAN FOREST ACCORDING TO ENVIRONMENTAL GRADIENTS AND DISTURBANCE REGIME
}

\author{
DYAKOV, N.*-ZHELEV, P. \\ Department of Dendrology, University of Forestry, \\ Climent Ohridski blv. 10, Sofia 1756, Bulgaria \\ *Corresponding author \\ e-mail:ndiakov@yahoo.com \\ (Received $3^{\text {rd }}$ January 2012; accepted $29^{\text {th }}$ January 2013)
}

\begin{abstract}
Forty two vegetation samples ( 0.1 ha nested field plots), taken from lowland riparian forest, located on the right floodplain of Tundzha river (Southeastern Bulgaria), were analyzed. Coarsest picture of vegetation pattern was outlined, using classification and ordination techniques. Detailed analysis of alien and native species distribution was carried out by correlation and regression methods. Described variables were tested for difference with parametric and nonparametric tests. Classification resulted in four plant community types, dominated by different native and exotic trees, shrubs and herbaceous species. Ordination showed that main environmental gradient responsible for the vegetation pattern explanation was habitat moisture. Correlation and regression analyses revealed that most abundant alien and invasive species, such as Acer negundo and Amorpha fruticosa, preferred the most humid part of the moisture gradient, but other alien species had complex response surfaces. Logging is considered as unreliable predictor of alien species distribution at 0.1 ha scale, but as a promoter for xerophylous alien herbs establishment at the $1 \mathrm{~m}^{2}$ scale on the studied territory. Flooding disturbance certainly has played essential role in this context too. Species diversity demonstrated patterns in accordance with Intermediate Disturbance Hypothesis. We recommend using different sampling scales with greater area covered.
\end{abstract}

Keywords: riparian forest, environmental gradients, alien species diversity

\section{Introduction}

Riparian habitats harbor numerous species, functioning as filters between land and water biotopes, and serving as pathways for migration and dispersal of different organisms. They are key systems for regulation of aquatic-terrestrial relationships and providing early indications of environmental change (Naiman and Décamps, 1997). Riparian vegetation has various important ecological functions, including provision of food, moderation of stream water temperature via shading, filtering sediments, nutrient control, and stabilization of river banks. They are considered as places of intensive human activity and management challenge (Richardson et al., 2007).

Many types of disturbances may occur in riparian habitats, such as hydrological alterations, resulting from dam construction or regulation of river channel; cultivation of crops, which cause sediment deposition and eutrophication; logging, grazing and trampling, water extraction or recreation (Richardson et al., 2007).

In the last twenty years much effort was put in the research of invasive species distribution and expansion of their areal over new territories. It is now known that riparian habitats are one of the most threatened sites of invasion. Riparian forests are vulnerable to invasion by exotic species because they are under recurrent disturbances and the water is available all year round (Planty-Tabacchi et al., 1996). Along with the transportation of propagules, rivers provide suitable habitat for colonizing species by fluvial deposition and erosion of sediment. In these conditions light and space are easily 
available and competition from extant species is reduced. Unoccupied sites became easily invaded by exotics, which benefit additionally by continual replenishment of nutrients from stream depositions, resulting in rapid growth of invasive and pioneer species (Tickner et al., 2001). These patterns are often even more pronounced along regulated rivers where natural communities are further disturbed (Nilsson and Berggren, 2000). Increased abundance of alien plants may be reason for radical alterations of the structure and functioning of riparian vegetation, or may have little influence on it, depending on the circumstances (Richardson et al., 2007).

The current descriptive study was designed and implemented to meet three objectives. 1) To examine to what extend alien species are established in the studied territory? 2) How establishment of alien species depend on environmental or disturbance gradients at two different spatial scales? 3) How this process correlates with native plant diversity.

\section{Methods}

\section{Study site}

Study site is located between $42^{\circ} 13^{\prime} 05^{\prime \prime}-42^{\circ} 11^{\prime} 00^{\prime \prime} \mathrm{N}$ and $26^{\circ} 33^{\prime} 31^{\prime \prime}-26^{\circ} 34^{\prime} 59^{\prime \prime} \mathrm{E}$ along the right riverbank of Tundzha river, Southeastern Bulgaria. Its territory (467.6 ha) was declared Maintained Reserve by the Bulgarian Legislation in 1999.

Conservation of Bulgarian inland riparian forests is worth the effort because of their rarity nowadays, found only along the lowland river channels of the Mediterranean basin (e.g. Maritza and Tundzha rivers) as small isolated spots. One of the last remaining riparian forests is conserved within the Maintained Reserve "Dolna Topchiya", which is subject of the current study.

Structure and species composition of the studied riparian forest are influenced by periodic floods, acting as a natural disturbance. They take place mainly during the winter and early spring. The water carries and deposits dead organic matter and numerous seeds downstream, as well as great quantities of sediment, promoting the successful germination of some species. Along with the native plant species different exotic species arrive and establish on the reserve territory. Some of these became naturalized or invasive (e.g. Acer negundo, Amorpha fruticosa), or even transformers (e.g. Amorpha fruticosa) (sensu Richardson et al., 2000). In this study we will follow the terminology of Richardson et al. (2000). Besides alien species, there were some species, native for the country, but expressing behavior of invaders under favorable conditions. Since they could affect and change the natural plant communities, these species were also considered for the analysis.

During the winter months each year, vegetation of previously selected part of the protected area is logged. This aims removing wind-broken and uprooted trees (mainly Fraxinus angustifolia subsp. oxycarpa) from past windstorm. They are also thought as promoting survival of some valuable tree species (e.g. Quercus robur) by elimination of other unwanted competitive trees (Fraxinus angustifolia subsp. oxycarpa, Acer campestre, Ulmus minor). Closest to the riverbed forest parts are spared from logging. Forest clearings are opened periodically in some places. These are assumed to be suitable habitat spots for the common pheasant (Phasianus colchicus colchicus), which is one of the desired native inhabitants of the reserve. Recently, measures for restoring and irrigation anew of one of the river's dead arms, passing through the whole reserve territory, were undertaken. It is assumed that this will lift up the water table and stop the 
progressive decline of Quercus robur - one of the valuable trees in the area. However, penetrating water through this new way will probably bring additional opportunity for alien species establishment.

We were concerned that these activities, along with natural disturbance phenomena, could increase the rate of dispersal and establishment of extant and new exotics in these riparian habitats and pose threats to native biodiversity.

\section{Field methods}

Total of 42 (0.1 ha) sample plots were set along preliminary drawn transects, so as to cover the whole territory of the reserve. Spacing samples at least $200 \mathrm{~m}$ apart avoided autocorrelation. Sampling plot is a rectangle with $50 \mathrm{~m}$ long and $20 \mathrm{~m}$ short side, along a $50 \mathrm{~m}$ tape at the middle line (Whittaker, 1956) (Fig. 1).

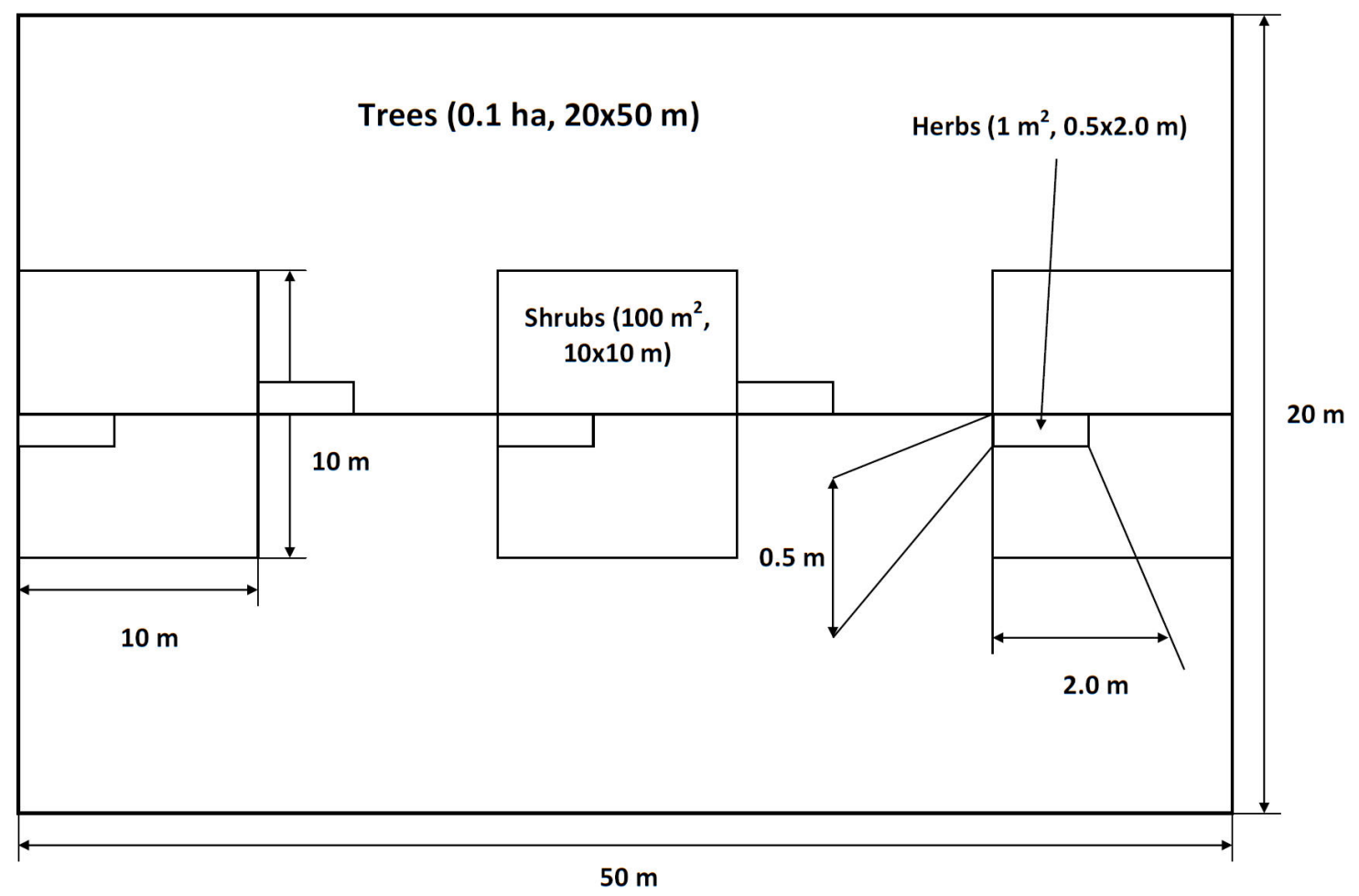

Figure 1. Nested sampling plot [modified from Whittaker (1956)]

Within this 0.1 ha plot all stems ( $>1 \mathrm{~cm}$ at breast height $\approx 1.40 \mathrm{~m}$ ) were measured for each species. Three additional $100 \mathrm{~m}^{2}(10 \times 10 \mathrm{~m})$ subplots were set along the tape (10 $\mathrm{m}$ apart from each other), where cover of all trees and shrubs $(<1 \mathrm{~cm}$ at breast height) was estimated. Cover estimation of the herbaceous species was done in another five $1 \mathrm{~m}^{2}(0.5 \times 2.0 \mathrm{~m})$ sub subplots, set along the tape $(8 \mathrm{~m}$ apart from each other). Whether to be on left or right side of the tape was determined by throwing a coin. At last, the whole 0.1 ha plot was searched for unrecorded species and these were given minimal Importance Value (IV). 
Calculation of species $I V$ was done the following way:

1) Tree and shrub stems $>1 \mathrm{~cm}$ at breast height (canopy stratum):

$I V=$ density (number of individuals)/0.1 ha (expressed in percents)

2) Tree and shrub stems $<1 \mathrm{~cm}$ at breast height (or less than $2 \mathrm{~m}$ height) (shrub stratum):

$I V=$ mean cover $/ 100 \mathrm{~m}^{2}+$ frequency $/ 2$

3) Trees, shrubs and herbs (herb stratum):

$I V=$ mean cover $/ 1 \mathrm{~m}^{2}+$ frequency/2

$I V s$ for a given species from different strata are summed. Cover is estimated visually in percents $(0-100 \%)$ and frequency is calculated by the following formula:

$C_{f}=\frac{a}{b} \cdot 100(\%)$.

Where

$a=$ number of subplots (for shrub stratum) or sub subplot (for herb stratum), where the species is present;

$b=$ total number of sampling subplots or sub subplots.

Exact altitude was measured in all sample plots by barometer-altimeter. At the beginning of the tape, GPS coordinates of all plots were taken. Distance from the sampling plot to the river bed was also measured. Information about the exact year and location of the logging carried out was provided by the reserve authorities.

\section{Data analysis}

Using the divisive classification algorithm of Two-Way INdicator SPecies ANalysis (TWINSPAN) (Hill, 1979), all samples were clustered into compositional groups or community types. Analysis was run with checked default program options. This method not only classifies the samples, but also constructs double-ordered table from the data matrix (samples $\times$ species). The software also produces indicator species for the resulting groups, which is another useful feature. Combination of these characteristics made it one of the most popular programs in vegetation ecology nowadays.

General picture of the environmental gradient interaction, influencing sample composition, was examined with indirect and direct gradient analysis, using Detrended Correspondence Analysis (DCA) (Hill and Gauch, 1980) and Canonical Correspondence Analysis (CCA) (ter Braak, 1986). DCA maximizes the separation between samples along latent environmental gradients (ordination axes), based on species composition. It is a powerful tool for detecting pattern of analyzed vegetation (Reed et al., 1993). As a method for direct gradient analysis, CCA explains the variation in the data on the basis of preliminary chosen environmental gradients. The main advantages of CCA are the simultaneous ordering of sites and species, rapid computation, very good performance when species have nonlinear and unimodal relationships to environmental gradients, and robustness to violation of preliminary assumptions (Palmer, 1993). Analyses were run with default program options. Significance of the extracted CCA axes was tested with Monte Carlo permutations.

Traditionally, vegetation structure and correlation of vegetation and environment have been analyzed at a single scale of observation, using one quadrate size. However, as Reed et al. (1993) emphasized, different ecological processes are important at different spatial and temporal scales and dependent on the scale of observation. We analyzed vegetation patterns at two different spatial scales using two data sets. First data 
set was composed of 420.1 ha field plots. Second one comprises 207 field subplots of $1 \mathrm{~m}^{2}$. Two different DCA and CCA ordinations were carried out with the two data sets.

Correlations between the alien species and environmental gradients were examined. Other vegetation variables like diversity indices, cover, and life forms were also correlated with the environmental gradients. Because the relationships between the species abundances and other variables were not linear (Krebs, 1999), Spearman rank correlation coefficient $\left(R_{s}\right)$ were used.

We measured species diversity with Hill's (1973) $N_{2}$. It is less dependent on the species number and sample size. Moreover, it is simple and easy for ecological interpretation (Peet, 1974). Evenness, another aspect of diversity, was estimated with Hill's $E$ '. According to Peet (1974), it depends only on the diversity indices, does not depend on the sample size, and represents a useful tool for species diversity investigation. We also measured species richness at the two deferent spatial scales, employed in this study.

Detailed analyses of the alien species distribution in the context of main environmental gradients were undertaken, using Generalized Additive Models (GAM) (Thomas and Mitchell, 1991). GAM maximizes the quality of the dependent variable description, which may have different distribution. This is done through building of nonparametric functions of independent variables, which are connected with the dependent variable by different link function (Thomas and Mitchell, 1991). Response surface shape in GAM is data driven, which is one of the advantages of the method compared to the parametric ones. As a result, features such as bimodality and asymmetry in the data can be easily detected (Thomas and Mitchell, 1991). Searching for the most appropriate model, we used a stepwise selection procedure, based on Akaike Information Criterion (AIC). AIC checks models for goodness of fit and parsimony, rejecting very complex ones (Carol et al., 2006). According to Thuiller et al. (2003) AIC allows the removal of variable redundancy and multicollinearity problems.

We compared different variables, using paired $t$-test when they had normal distribution and Mann-Whitney Rank Sum Test when they had non-normal distribution. Statistical level of significance in all analyses and tests was set $\alpha=0.05$.

All graphs and statistical analyses were done, using the following software products: CANOCO for Windows, version 4.51 (ter Braak and Smilauer, 2003), TWINSPAN for Windows, version 2.3 (Hill and Smilauer, 2005), CanoDraw for Windows, version 4.1 (Smilauer, 2003), STATISTICA, version 8.0 (StatSoft, 2004), SigmaPlot for Windows, version 11.0 (Systat Software, Inc., 2008). All distances are measured using Garmin eTrex Legend Global Positioning System and MapSource software, Version 6.11.6 (Garmin Ltd.)

\section{Results}

\section{Classification}

In the set 420.1 ha plots, totally 170 vascular plant species were found. Some species were hard to identify on the field, therefore, specimens were collected and taken for laboratory identification.

TWINSPAN classification of all 42 samples resulted in four groups (Table 1). We used three levels of division and obtained groups on the third level are shown. Names of the groups were given on the basis of dominant tree, shrub or herb species. The program produced at least two indicator species for each group, which are given in Bold for 
corresponding group. These are listed in the top part of Table 1. The middle part of the table contains mean values of the used environmental gradients by groups, mean cover of tree, shrub and herb layers, mean species number of the five plant functional groups (e.g. tee, shrub, perennial, biannual, annual), and mean values of diversity indices of all and alien species only. At the bottom of the table, major alien and invasive species are shown. For the indicator and alien species, mean importance value and frequency in the corresponding group is shown.

Table 1. TWINSPAN classification of plant communities. Means with SE in parentheses are shown. With Bold are marked indicator species' Importance Values and frequency for the corresponding TWINSPAN group. Values in the rows with the same letter are not significantly different $(P \leq 0.05)$. IV=mean importance value; $F=$ frequency in the group (\%)

\begin{tabular}{|c|c|c|c|c|}
\hline TWINSPAN groups & $\begin{array}{c}\text { Acer campestre- } \\
\text { Crataegus } \\
\text { monogyna } \\
(n=15)\end{array}$ & $\begin{array}{c}\text { Ulmus minor- } \\
\text { Acer } \\
\text { campestre- } \\
\text { Fraxinus } \\
\text { oxycarpa } \\
(n=13)\end{array}$ & $\begin{array}{c}\text { Acer } \\
\text { negundo- } \\
\text { Fraxinus } \\
\text { oxycarpa } \\
(n=9)\end{array}$ & $\begin{array}{c}\text { Acer } \\
\text { negundo- } \\
\text { Rubus } \\
\text { canescens } \\
(n=5)\end{array}$ \\
\hline & $\mathbf{A}$ & B & $\mathbf{C}$ & $\mathbf{D}$ \\
\hline Indicator species & $I V / F$ & $I V / F$ & $I V / F$ & $I V / F$ \\
\hline Chaerophyllum temulentum & $3.6 / 33$ & 44.6/100 & 13.6/100 & $2.0 / 20$ \\
\hline Chelidonium majus & $0.7 / 6.7$ & $2.5 / 8$ & $16.9 / 100$ & $18.4 / 100$ \\
\hline Daucus carrota & $2.0 / 20$ & $0 / 0$ & $0 / 0$ & $0 / 0$ \\
\hline Festuca gigantea & $0 / 0$ & $29.2 / 100$ & $12.4 / 89$ & $2.0 / 20$ \\
\hline Lycopus europaeus & $0 / 0$ & $0.8 / 8$ & $2.2 / 22$ & $2.0 / 20$ \\
\hline Myrrhoides nodosa & $6.9 / 47$ & $0 / 0$ & $0 / 0$ & 8.8/80 \\
\hline Parietaria officinalis & $1.3 / 13$ & $1.6 / 15$ & $2.3 / 22$ & 11.5/100 \\
\hline \multicolumn{5}{|l|}{ Environmental gradients } \\
\hline Mean elevation (m) & $111.47(0.42) \mathrm{a}$ & $109.69(0.52) \mathrm{b}$ & $\begin{array}{l}107.44 \\
(0.80) \mathrm{c}\end{array}$ & $\begin{array}{l}110.80 \\
(0.58) \mathrm{ab}\end{array}$ \\
\hline Mean distance from the river (m) & $417.67(61.81) \mathrm{a}$ & $462.62(71.44) \mathrm{a}$ & $24.11(7.30) \mathrm{b}$ & $\begin{array}{l}99.80 \\
(84.93) b\end{array}$ \\
\hline $\begin{array}{l}\text { Mean number of years after } \\
\text { logging }\end{array}$ & $2.47(0.41) \mathrm{a}$ & $5.00(0.16) b$ & $9.56(0.44) \mathrm{c}$ & $10.00(0.00) \mathrm{c}$ \\
\hline \multicolumn{5}{|l|}{ Mean cover $(\%)$} \\
\hline Trees (0.1 ha) & $63.33(2.69) \mathrm{a}$ & $67.69(2.87) \mathrm{a}$ & $82.22(2.78) b$ & $85.00(3.87) \mathrm{b}$ \\
\hline Shrubs $\left(100 \mathrm{~m}^{2}\right)$ & $20.67(1.94) \mathrm{a}$ & $21.34(6.20) \mathrm{ac}$ & $5.71(0.65) b c$ & $16.40(2.29) \mathrm{a}$ \\
\hline Herbs $\left(1 \mathrm{~m}^{2}\right)$ & $23.87(2.21) \mathrm{ac}$ & $30.83(3.03) \mathrm{a}$ & $\begin{array}{l}18.80 \\
(4.06) b c\end{array}$ & $33.32(4.34) \mathrm{a}$ \\
\hline \multicolumn{5}{|l|}{$\begin{array}{l}\text { Functional type (mean species } \\
\text { number/0.1 ha) }\end{array}$} \\
\hline Tree & $7.40(0.21) \mathrm{a}$ & $7.38(0.31) \mathrm{a}$ & $10.78(0.46) b$ & $9.20(0.86) b$ \\
\hline Shrub & $6.40(0.64) \mathrm{ac}$ & $5.69(0.43) \mathrm{a}$ & $7.33(0.71) b c$ & $7.80(1.02) b c$ \\
\hline Perennial & $17.20(1.14) \mathrm{a}$ & $17.69(1.40) \mathrm{a}$ & $12.78(0.52) b$ & $9.40(0.87) \mathrm{c}$ \\
\hline Biennial & $1.47(0.27)$ & $0.92(0.26)$ & $0.67(0.24)$ & $0.80(0.37)$ \\
\hline Annual & $4.80(0.83) \mathrm{a}$ & $2.85(0.45) \mathrm{ab}$ & $2.44(0.50) \mathrm{ab}$ & $1.60(0.24) b$ \\
\hline \multicolumn{5}{|l|}{ Diversity } \\
\hline Mean number of species/0.1 ha & $37.33(18.90) \mathrm{a}$ & $34.54(23.48) \mathrm{ab}$ & $34.22(9.67) \mathrm{a}$ & $\begin{array}{l}29.00 \\
(12.19) \mathrm{b}\end{array}$ \\
\hline Mean number of species $/ 1 \mathrm{~m}^{2}$ & $7.54(0.46) \mathrm{a}$ & $9.32(0.73) b$ & $4.49(0.43) \mathrm{c}$ & $4.68(0.89) \mathrm{c}$ \\
\hline $\begin{array}{l}\text { Mean index of species diversity } \\
\left(\mathrm{N}_{2}\right)\end{array}$ & $17.71(0.98) \mathrm{a}$ & $19.12(1.24) \mathrm{a}$ & $15.98(1.04) \mathrm{a}$ & $12.07(0.88) b$ \\
\hline Mean index of evenness $\left(E^{\prime}\right)$ & $0.72(0.01) \mathrm{a}$ & $0.78(0.01) \mathrm{b}$ & $0.71(0.02) \mathrm{a}$ & $0.69(0.03) \mathrm{a}$ \\
\hline
\end{tabular}


Table 1. cont.

\begin{tabular}{|c|c|c|c|c|}
\hline TWINSPAN groups & $\begin{array}{c}\text { Acer } \\
\text { campestre- } \\
\text { Crataegus } \\
\text { monogyna } \\
(n=15)\end{array}$ & $\begin{array}{c}\text { Ulmus minor- } \\
\text { Acer } \\
\text { campestre- } \\
\text { Fraxinus } \\
\text { oxycarpa } \\
(n=13)\end{array}$ & $\begin{array}{c}\text { Acer negundo- } \\
\text { Fraxinus } \\
\text { oxycarpa } \\
(n=9)\end{array}$ & $\begin{array}{c}\text { Acer negundo- } \\
\text { Rubus } \\
\text { canescens } \\
(n=5)\end{array}$ \\
\hline & $\mathbf{A}$ & B & $\mathbf{C}$ & $\mathbf{D}$ \\
\hline \multicolumn{5}{|l|}{ Alien species } \\
\hline $\begin{array}{l}\text { Mean number of } \\
\text { species/0.1 ha }\end{array}$ & 9.87(1.31)ac & 6.62(0.91)a & $11.78(0.78) \mathrm{bc}$ & $9.80(0.80) \mathrm{ac}$ \\
\hline $\begin{array}{l}\text { Mean percentage alien species of } \\
\text { total flora }\end{array}$ & $5.80(0.77) \mathrm{ac}$ & $3.89(0.54) \mathrm{a}$ & $6.93(0.46) b c$ & $5.76(0.47) \mathrm{ac}$ \\
\hline $\begin{array}{l}\text { Mean percentage alien species in } \\
\text { the group }\end{array}$ & $25.70(2.64) \mathrm{a}$ & $11.00(1.08) \mathrm{b}$ & $34.35(1.72) \mathrm{c}$ & $33.66(1.62) \mathrm{ac}$ \\
\hline $\begin{array}{l}\text { Mean Importance Value of all } \\
\text { alien species in the group }\end{array}$ & $1.89(0.23) \mathrm{a}$ & $1.84(0.29) \mathrm{a}$ & $4.22(0.39) \mathrm{b}$ & $5.12(0.29) b$ \\
\hline $\begin{array}{l}\text { Most abundant alien and } \\
\text { invasive species }\end{array}$ & $I V / F$ & $I V / F$ & $I V / F$ & $I V / F$ \\
\hline Acer negundo & $0.67 / 7$ & $0 / 0$ & $78.24 / 89$ & $103.31 / 100$ \\
\hline Amorpha fruticosa & $0.67 / 7$ & $0 / 0$ & $16.51 / 78$ & $39.20 / 100$ \\
\hline Arctium lappa $n^{*}$ & $6.18 / 60$ & $6.21 / 62$ & $5.56 / 56$ & $6.01 / 60$ \\
\hline Aristolochia clematitis $n$ & $4.56 / 27$ & $5.56 / 38$ & $14.96 / 100$ & $22.22 / 100$ \\
\hline Cirsium arvense $n$ & $3.34 / 33$ & $0.78 / 8$ & $0 / 0$ & $0 / 0$ \\
\hline Conyza canadensis & $2.00 / 20$ & $0.77 / 8$ & $0 / 0$ & $0 / 0$ \\
\hline Cucubalus baccifer $n$ & $6.22 / 60$ & $13.65 / 69$ & $12.29 / 100$ & $4.00 / 40$ \\
\hline Fallopia convolvulus $n$ & $4.00 / 40$ & $3.86 / 23$ & $0 / 0$ & $0 / 0$ \\
\hline Galega officinalis $n$ & $5.50 / 53$ & $1.54 / 15$ & $0 / 0$ & $0 / 0$ \\
\hline Galium apparine $n$ & $4.86 / 27$ & $3.08 / 31$ & $1.11 / 11$ & $0 / 0$ \\
\hline Gleditchia triacanthos & $0 / 0$ & $1.54 / 15$ & $7.22 / 44$ & $0 / 0$ \\
\hline Humulus lupulus $n$ & $0.67 / 7$ & $0.77 / 8$ & $9.17 / 67$ & $4.00 / 40$ \\
\hline Lapsana communis $n$ & $9.34 / 80$ & $10.02 / 77$ & $6.78 / 67$ & $0 / 0$ \\
\hline Melilotus albus $n$ & $5.34 / 53$ & $1.58 / 15$ & $1.11 / 11$ & $0 / 0$ \\
\hline Morus alba & $0.67 / 7$ & $0.84 / 8$ & $4.72 / 78$ & $11.54 / 100$ \\
\hline Prunus cerasifera $n$ & $6.55 / 60$ & $10.15 / 69$ & $14.70 / 78$ & $10.87 / 60$ \\
\hline Prunus spinosa $n$ & $3.99 / 27$ & $14.56 / 38$ & $4.51 / 11$ & $2.91 / 20$ \\
\hline Sonchus arvensis $n$ & $4.00 / 40$ & $2.34 / 15$ & $0 / 0$ & $0 / 0$ \\
\hline Urtica dioica $n$ & $4.00 / 40$ & $15.88 / 77$ & $31.62 / 100$ & $50.87 / 100$ \\
\hline
\end{tabular}

First community type Acer campestre-Crataegus monogyna $(n=15)$ occupies more elevated and relatively xeric habitats, located on a greater distance from the river. These communities were logged in the last 1-4 years. Tree canopy is well developed, but its cover is not rather high. Besides Acer campestre and Crataegus monogyna, here dominate tree species like Fraxinus angustifolia subsp. oxycarpa (referred hereafter as F. oxycarpa), Ulmus minor and Quercus robur. Shrub and herb layers are well developed, with dominating species like Ligustrum vulgare, Rubus canescens, Corylus avellana, Clematis viticella, Brachypodium sylvaticum and Geum urbanum. Dominating functional types are perennials and trees. Species richness/0.1 ha is highest, reaching average of 37.33 species, but not so high at $1 \mathrm{~m}^{2}$ scale, which is 7.54 species. Indices of diversity and evenness were also high, but not the highest ones. Species richness of aliens and invaders/0.1 ha is second highest. Most abundant were species like Lapsana communis, Arctium lappa, Cucubalus baccifer and Prunus cerasifera. 
Second TWINSPAN group is Ulmus minor-Acer campestre-Fraxinus oxycarpa $(n=13)$. These plant communities are distributed on moderately elevated sites of the river floodplain, which are located most far away from river bed. Logging has taken place here mainly 4-6 years ago. Tree layer is well developed, but the canopy is not highly closed and excess light penetrates to the forest floor. Shrub and herb layers are well developed. Together with the dominating tree species, other important tree, shrub and herb species are Crataegus monogyna, Quercus robur, Chaerophyllum temulentum, Dactylis glomerata, Festuca gigantea, Cornus mas and Acer tataricum. Dominant functional type here is perennial herbs, followed by tree and shrub types. Species richness/0.1 ha is the second highest, reaching 34.54 species, but at $1 \mathrm{~m}^{2}$ is highest among all community types -9.32 species. Indices of diversity and evenness are highest among all described community types. Contrary to some known hypotheses (Stohlgren et al., 2003), alien and invader species diversity here is lesser, reaching only 6.62 species/0.1 ha. Most abundant of them are again Lapsana communis, Arctium lappa, Cucubalus baccifer, but also Urtica dioica and Prunus spinosa.

Acer negundo-Fraxinus oxycarpa $(n=9)$ communities occupy less elevated concave habitats, distributed mainly close to the river bed. Commonly, in these habitats abundant moisture is available year-round. In the major part of these habitats logging has not been carried out in the last ten or more years. The canopy is well developed and highly closed. Dominant tree species here is the invader Acer negundo, together with Fraxinus oxycarpa. Other important trees are Ulmus laevis, Ulmus minor and Populus canescens. Shrub and herb layers are less developed. They are represented mainly by shade-tolerant species such as Rubus canescens, Urtica dioica, Sambucus nigra, Chelidonium majus, Amoprha fruticosa and Aristolochia clematitis. Here, like previous community types, dominant functional type is perennials, closely followed by trees. Mean number of plant species/ 0.1 ha is relatively high and reaches 34.22 species, but species richness $/ 1 \mathrm{~m}^{2}$ is least high among all plant communities, reaching only 4.49 species. This is probably caused from high canopy closure and very scarce light penetration to the forest floor. Alien and invasive species richness, however, is the highest among all communities. Dominant invasive species here are Acer negundo and Amorpha fruticosa. Other invaders are Aristolochia clematitis, Urtica dioica and Cucubalus baccifer.

The last TWINSPAN group is Acer negundo-Rubus canescens $(n=5)$. These forests are developed on moderately to highly elevated sites, located closer to the river channel. Like the former community type, these sites were spared from logging for the last 10 or more years. Canopy closure here is highest, but despite that, shrub and herb layers are well developed too. Dominant tree species, together with Acer negundo, are Populus canescens, Fraxinus oxycarpa and Ulmus minor. In the shrub and herb layers, species like Urtica dioica, Amorpha fruticosa, Hedera helix, Aristolochia clematitis, Parietaria officianalis and Geranium robertianum dominate. The first two dominant functional types have almost equivalent values. These are perennials and trees, closely followed by the shrubs. Species richness/0.1 ha is lowest, with only 29 species. Richness $/ 1 \mathrm{~m}^{2}$ is also very low, reaching only 4.68 species. Species diversity and evenness are lowest among all community types. Alien and invasive species diversity is relatively high, reaching average of 9.80 species/ 0.1 ha. Like the previous community type, dominant species are Acer negundo, Amorpha fruticosa, Aristolochia clematitis, but also Morus alba, Urtica dioica and Prunus cerasifera.

Described plant community types were compared by the most vegetation variables in Table 1. As can be seen from the table, we have found significant differences between 
the groups in many aspects. For example, Acer campestre-Crataegus monogyna and Ulmus minor-Acer campestre-Fraxinus oxycarpa differ from the others by the mean distance from the river bed, as well as by the mean number of years after logging. Acer negundo-Fraxinus excelsior is significantly different from the others by the mean elevation gradient values. Acer campestre-Crataegus monogyna and Ulmus minor-Acer campestre-Fraxinus oxycarpa are significantly different from Acer negundo-Fraxinus excelsior and Acer negundo-Rubus canescens by the canopy cover and the mean number of tree and perennial species/0.1 ha. Acer negundo-Fraxinus excelsior and Acer negundo-Rubus canescens are significantly richer in species from Acer campestreCrataegus monogyna and Ulmus minor-Acer campestre-Fraxinus oxycarpa at $1 \mathrm{~m}^{2}$ scale. Acer negundo-Rubus canescens is significantly less diverse from the rest of plant communities and Ulmus minor-Acer campestre-Fraxinus oxycarpa has significantly higher evenness than the others. Communities Acer campestre-Crataegus monogyna, Ulmus minor-Acer campestre-Fraxinus oxycarpa and Acer negundo-Fraxinus excelsior are significantly different by the mean percentage of alien and invasive species of all species in the group. And at last, Acer campestre-Crataegus monogyna and Ulmus minor-Acer campestre-Fraxinus oxycarpa are significantly different from Acer negundo-Fraxinus excelsior and Acer negundo-Rubus canescens by the mean importance value of all alien species in the group. In conclusion, it should be noted that type community Acer negundo-Fraxinus excelsior differs significantly by the most variables from Acer campestre-Crataegus monogyna and Ulmus minor-Acer campestreFraxinus oxycarpa, sometimes together with Acer negundo-Rubus canescens.

\section{Ordination}

Coarsest picture of the relationship between studied vegetation and environmental gradients is outlined with direct ordination analysis. CCA biplot of the analyzed 42 samples is shown on Figure 2. TWINSPAN groups are noted with different capital letters and environmental gradients with arrows. First CCA axis (the abscissa) is expression of the moisture gradient (water table depth), beginning from the moist riparian sites, located closely to the river channel, passing toward the more remote and xeric habitats, away from the river. Community types, dominated by Acer negundo (D and C) are grouped together in the right part of the diagram, i.e. in habitats, which are more humid and with lower altitude. These habitats are also spared from logging in the resent years, but they are under the influence of more or less frequent flood disturbance by the river. Communities, dominated by Acer campestre and Ulmus minor (A and B), are more closely related to habitats, located at greater distance from the river, having higher elevation. 


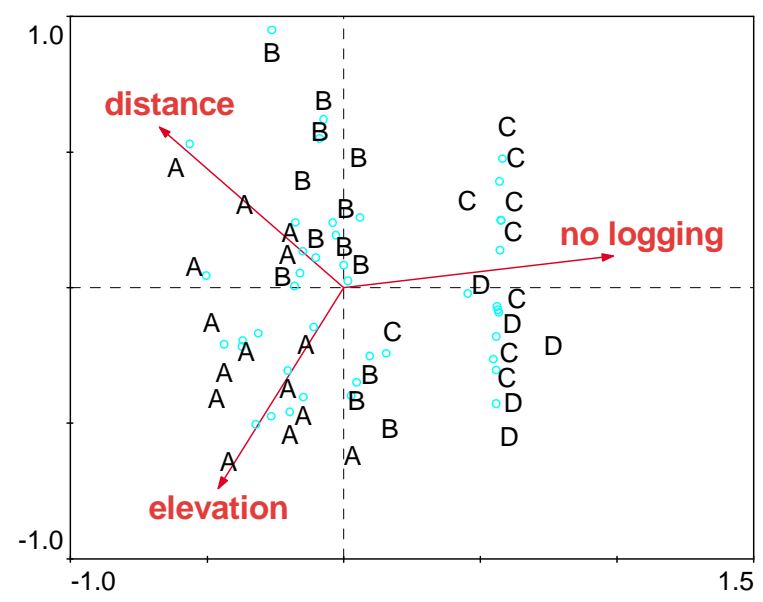

Figure 2. Ordination of all 420.1 ha samples together with used environmental gradients. $\boldsymbol{A}=$ Acer campestre-Crataegus monogyna $(n=15), \boldsymbol{B}=U l m u s$ minor-Acer campestre-Fraxinus oxycarpa (n=13), $\boldsymbol{C}=$ Acer negundo-Fraxinus oxycarpa ( $n=9), \quad \boldsymbol{D}=$ Acer negundo-Rubus canescens $(n=5)$. distance $=$ Distance to the river bed; no logging $=$ Years after logging

Statistical parameters of the CCA analyses at the two spatial scales are shown in Table 2. As can be seen, all CCA axes at the two scales are statistically significant. In other words, the number of significant environmental gradients does not increase with the plot size. There is discrepancy between our results and these of Reed et al.'s (1993), where significance of CCA axes increased with grain size. But we support Reed et al.'s (1993) first hypothesis that the correlation between environment and vegetation increases with increasing scale. It is evident from DCA axes correlation with environmental gradients (Table 3). For all compared correlation coefficients for the two scales, the stronger ones are those for the $1000 \mathrm{~m}^{2}$ scale.

Table 2. Eigenvalues and statistical significance of CCA axes at the two scales of measurement

\begin{tabular}{|c|c|c|c|c|c|}
\hline \multicolumn{6}{|c|}{$1000 \mathrm{~m}^{2}$ scale $(N=42)$} \\
\hline CCA axes & 1 & 2 & 3 & 4 & Total inertia \\
\hline Eigenvalues (EV) & 0.432 & 0.081 & 0.076 & 0.245 & 2.706 \\
\hline \multicolumn{6}{|c|}{ Monte Carlo test for significance of first and all CCA axes (499 permutations) } \\
\hline First CCA axis & & & & $\mathrm{F}=7.211$ & $P=0.002$ \\
\hline All CCA axes & & & & $\mathrm{F}=3.524$ & $P=0.002$ \\
\hline \multicolumn{6}{|l|}{$1 \mathrm{~m}^{2}$ scale $(N=207)$} \\
\hline CCA axes & 1 & 2 & 3 & 4 & Total inertia \\
\hline Eigenvalues (EV) & 0.688 & 0.661 & 0.505 & 0.367 & 18.767 \\
\hline \multicolumn{6}{|c|}{ Monte Carlo test for significance of first and all CCA axes (499 permutations) } \\
\hline First CCA axis & & & & $\mathrm{F}=6.846$ & $P=0.002$ \\
\hline All CCA axes & & & & $\mathrm{F}=2.488$ & $P=0.002$ \\
\hline
\end{tabular}

We also found support to Reed et al.'s (1993) second hypothesis that environmental variables strongly correlated with vegetation should be consistent across different scales. As can be seen form Table 3, the logging gradient is most strongly correlated with first DCA axis, and this holds for the two scales. It is followed by the distance gradient, and the most weakly correlated is elevation. Finally, we found support for the fourth hypothesis of Reed et al. (1993) that correlation between environment and 
vegetation is stronger for the data set with greater extent. The more extensive data set is that at $1000 \mathrm{~m}^{2}$ spatial scale. From Table 3 it is also evident that the significant correlations between first DCA axes and alien species variables are stronger at the $1 \mathrm{~m}^{2}$ scale, which is indication that the ecological processes at that scale are more important for their survival and distribution. Bottom part of the Table 3 shows that the unexplained variation at the $1 \mathrm{~m}^{2}$ scale is much greater - with longer gradients and higher eigenvalues. This is probably outcome from the greater heterogeneity of the samples at this scale.

Table 3. Correlation coefficients (Spearman index, $R_{s}$ ) between the DCA axes, some vegetation variables and environmental gradients used. Correlation coefficients $>0.5$ are marked with Bold. $n s=$ not significant. $* * * P<0.001 ; * * P<0.01 ; * P<0.05$.

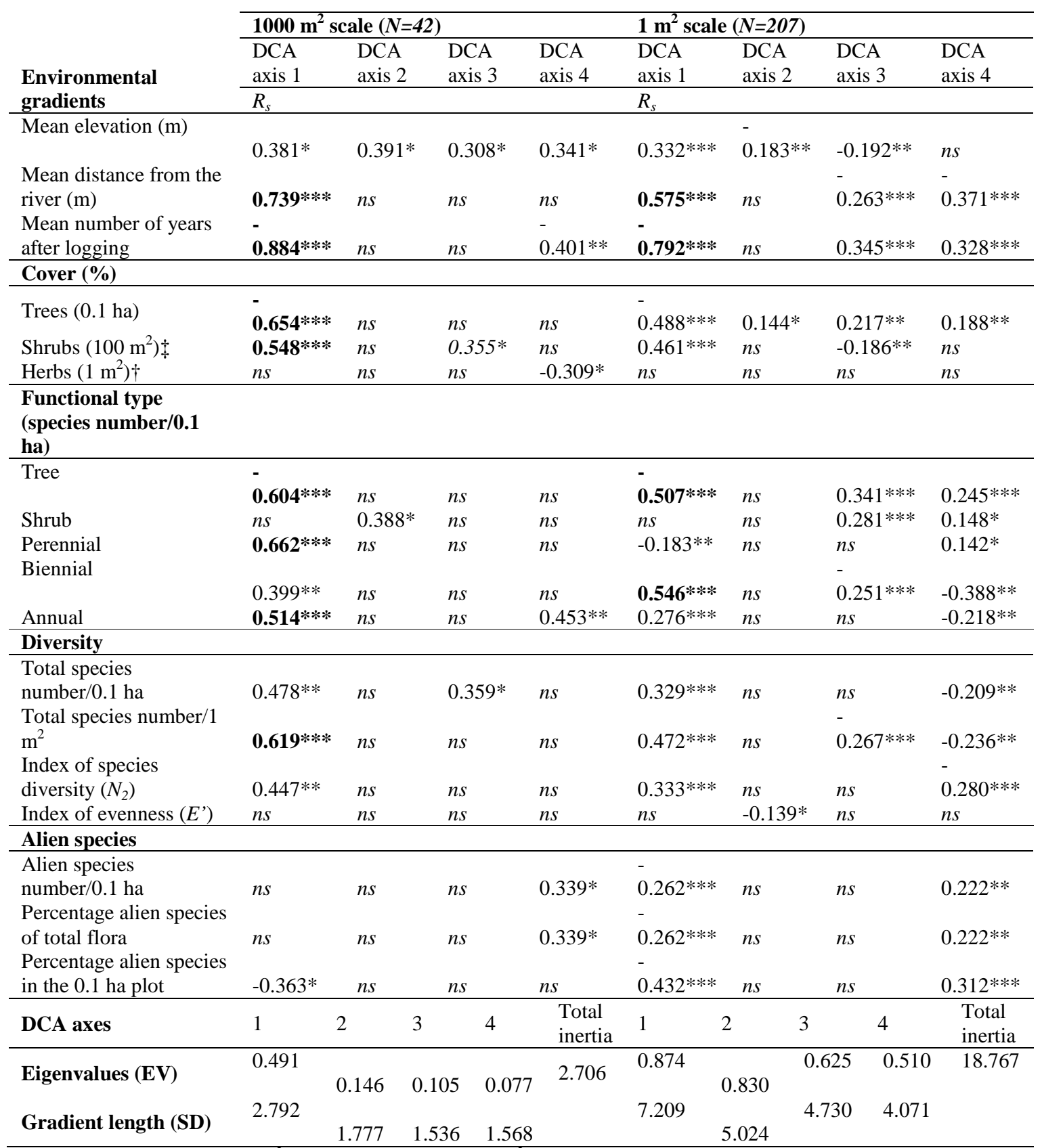

+ Shrub mean cover $/ 100 \mathrm{~m}^{2}$. + Herb mean cover $/ 1 \mathrm{~m}^{2}$. 
First DCA axis is expression of the humidity and logging pressure gradients. For the $1 \mathrm{~m}^{2}$ scale, it is evident that the alien species are strongly negatively correlated with unlogged stands. Logging obviously plays a role in the establishment of more aliens on the studied territory, and especially those preferring more xeric and open habitat conditions.

Figure 3 shows the result of CCA ordination of the most abundant alien and invasive species in the studied territory together with the main environmental gradients. The biplot shows the relative position of these species in the environmental space. The alien and invasive species are divided in two groups. Some of them, preferring more humid riparian sites, like Acer negundo, Amorpha fruticosa, Morus alba, are situated in the left part of the graph. Others are located in the right part of the diagram, where the habitats are more xeric, more open, and where logging was part of the resent year's management of the forest. These are Melilotus albus, Galega officinalis, Sonchus arvensis, etc. Alien and invasive species distribution will be analyzed in more details in the later sections.

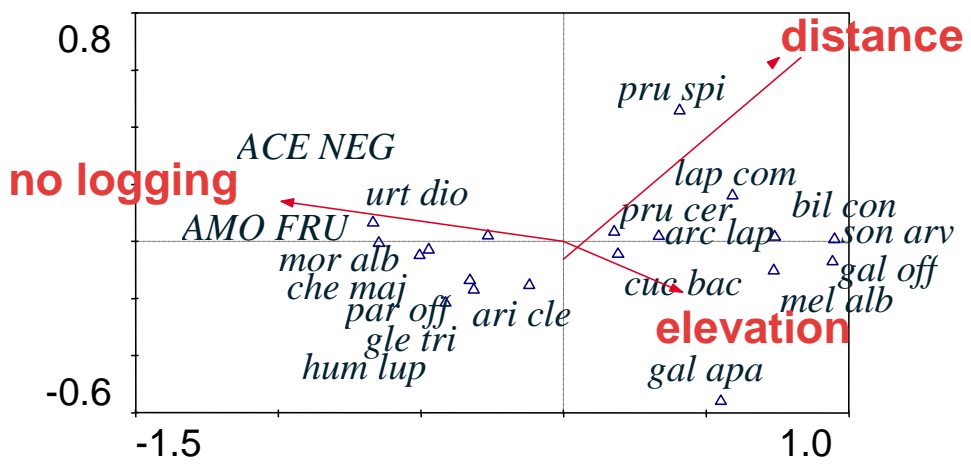

Figure 3. Ordination of some of the most abundant alien and invasive species together with the environmental and disturbance gradients. Species names are given with the first three letter of their genus and species name as follows: ACE NEG - Acer negundo; AMO FRU - Amorpha fruticosa; arc lap - Arctium lappa; ari cle - Aristolochia clematitis; bil con - Fallopia convolvulus; che maj - Chelidonium majus; cuc bac - Cucubalus baccifer; gal off - Galega officinalis; gal apa - Galium aparine; gle tri - Gleditchia triacanthos; hum lup - Humulus lupulus; lap com - Lapsana communis; mel alb - Melilotus albus; mor alb - Morus alba; par off - Parietaria officinalis; pru cer - Prunus cerasifera; pru spi - Prunus spinosa; son arv Sonchus arvensis; urt dio - Urtica dioica. distance=Distance to the river bed; no logging $=$ Years after logging

Aiming to test our interpretation of CCA analysis we correlated the major alien and invasive species distribution with the environmental gradients and all other vegetation variables measured. Results are shown in Table 4. Strongest correlation among the trees demonstrated Acer negundo and Morus alba. They are negatively correlated with the distance to the river and positively correlated with unlogged forests. Acer negundo is also negatively correlated with the elevation. Both species are negatively correlated with the species richness $/ 1 \mathrm{~m}^{2}$, but strongly positively correlated with the tree cover and tree number/0.1 ha. Both species are negatively correlated with perennial species number/0.1 ha. Among the shrubs, Amorpha fruticosa demonstrates similar correlations as Acer negundo. This species is also strongly negatively correlated with the diversity and evenness of the communities. 
Table 4. Correlation coefficients (Spearman index, $R_{s}$ ) between the most abundant alien and invasive species, some vegetation variables and used environmental gradients. Correlation coefficients $>0.5$ are marked with Bold. $n s=$ Not significant. $* P<0.05 ; * * P<0.01$

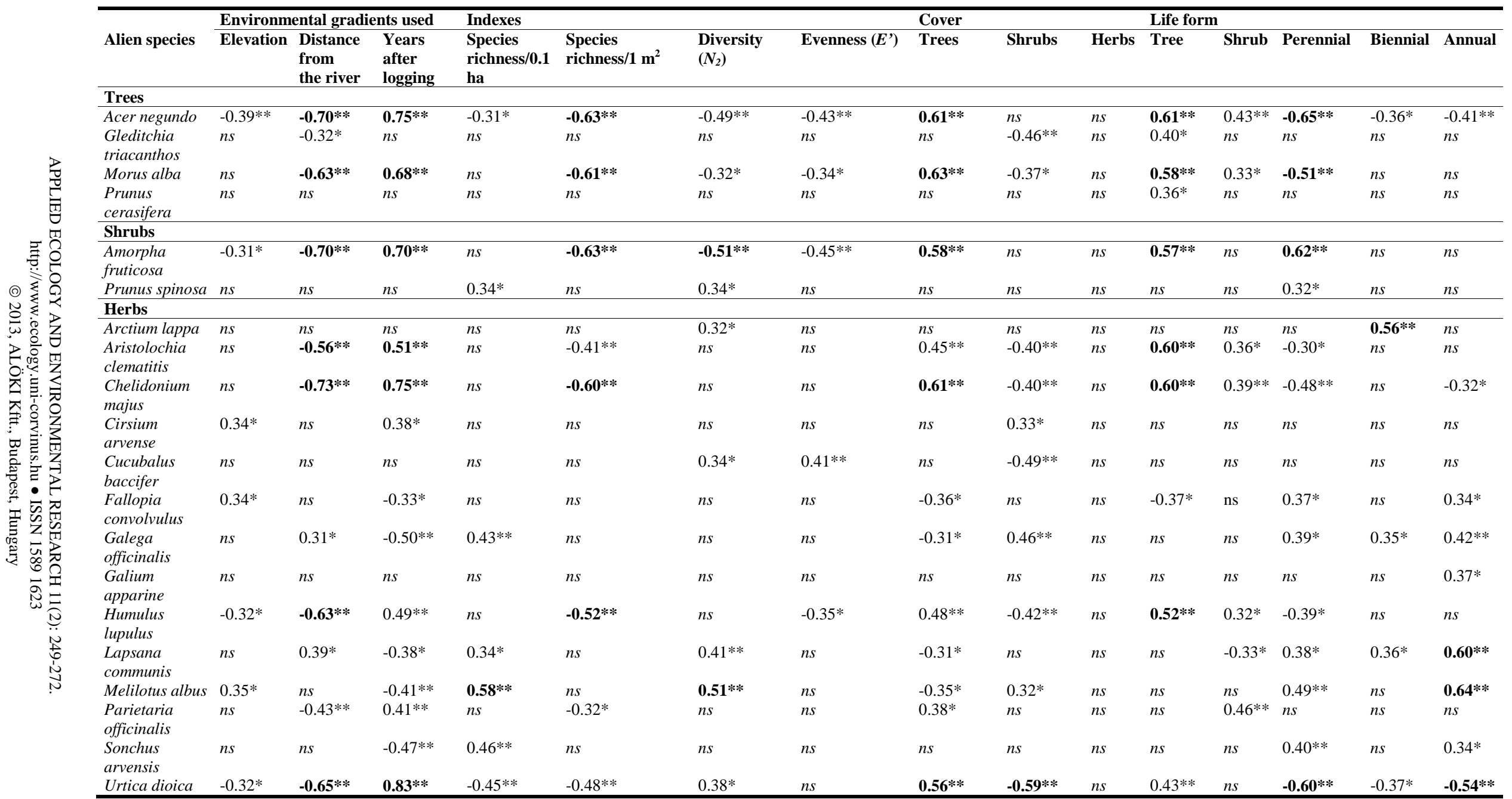


Most of the alien and invasive herbs demonstrate similar correlation patterns, but there are some differences too. Most of them do not correlate significant with the elevation. Others are positively (Cirsium arvense, Fallopia convolvulus and Melilotus albus) or negatively (Humulus lupulus and Urtica dioica) correlated with this gradient. Most of the alien herbs are negatively correlated with the distance to the river. Aristolochia clematitis, Chelidonium majus and Urtica dioica are strongly positively correlated with unlogged forests, while species like Galega officinalis, Sonchus arvensis and Melilotus albus are positively correlated with logged ones. Most of the herbs are indifferent towards species richness/0.1 ha with the exception of Melilotus albus, Sonchus arvensis, Galega officinalis and Lapsana communis, which correlate positively with it.

Strong negative correlations with species richness $/ 1 \mathrm{~m}^{2}$ demonstrate species like Chelidonium majus, Humulus lupulus and Urtica dioica. Herb aliens demonstrate strong negative or positive correlation with tree and shrub cover, but none of them is significantly correlated with herb cover (Table 3). Here should be mentioned the strong positive correlations of Aristolochia clematitis, Chelidonium majus, Humulus lupulus and Urtica dioica with tree species number/0.1 ha. Urtica dioica is also strongly negatively correlated with perennial and annual species number/0.1 ha. Strongly positively correlated with annual species number are Lapsana communis and Melilotus albus. Arctium lappa is highly positively correlated with biennial species number/0.1 ha.

\section{Diversity}

Graphical manner to represent the diversity pattern of described plant communities are dominance-diversity curves (Whittaker, 1956) (Fig. 4).

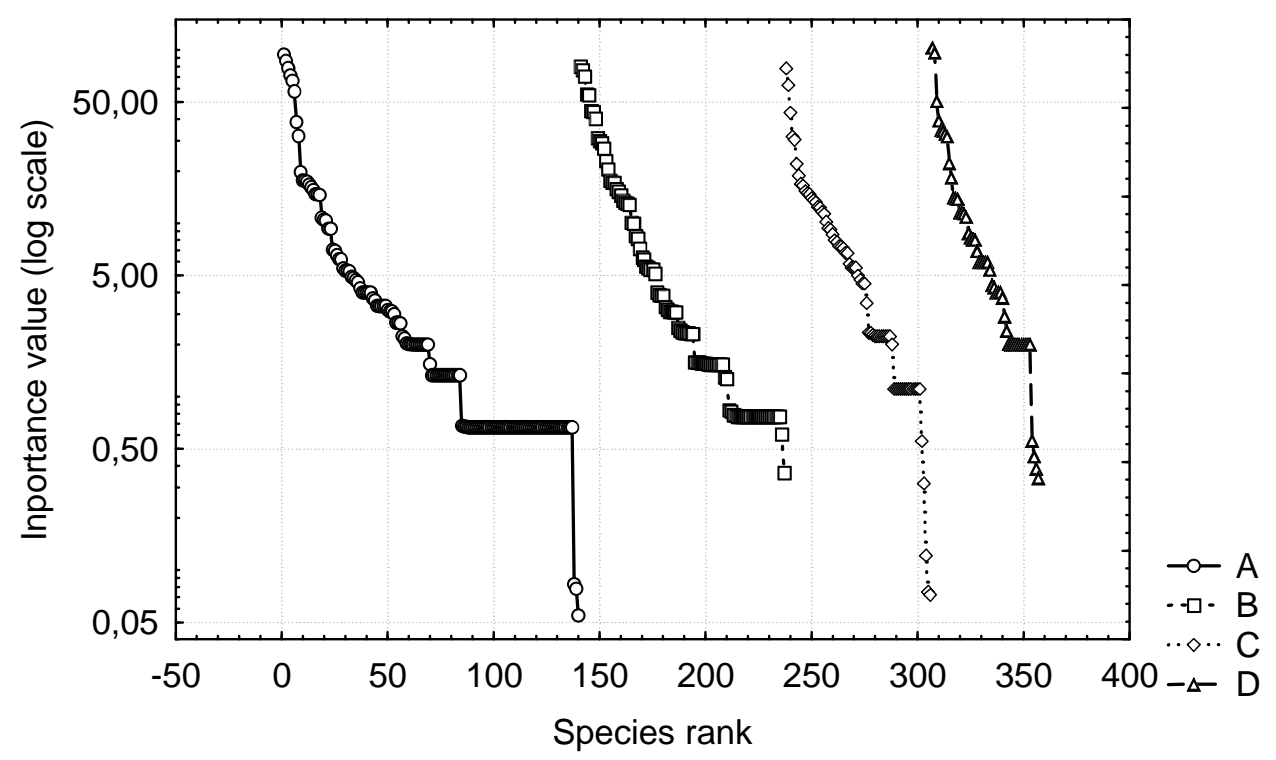

Figure 4. Dominance-diversity curves, showing diversity pattern of the four TWINSPAN communities. Plant communities are indicated with capital letters (see Fig. 2)

All species in the community from the most to the least abundant are arranged on the abscissa. On the ordinate (log scale) are depicted species' Importance Values. It can be seen that the left two curves are longer and more inclined, which means that they have 
more species and their abundance is more evenly distributed in the community. The two right curves are shorter and steeper. They have less species with more uneven distribution. The latter two communities are dominated by Acer negundo and have significantly higher Importance Values of all alien and invasive species (see Table 1).

Diversity patterns of all species, and alien and invasive species only, in the environmental space defined by elevation, logging and habitat moisture (distance to the river bed) were analyzed with Generalized Additive Models (GAM). The results are illustrated on Fig. 5. Response surface distribution and regression model significance are shown in Table 5. Fig. 5A illustrate species diversity pattern. Most diverse communities are found in the relatively xeric, low-elevated habitats, with logging activities in the last 4-6 years. Species number/0.1 ha reaches maximum of 54 species. Communities distributed in more humid riverside habitats, where logging has not taken place in the last 10 or more years, are less diverse, with species number, reaching average of 29 species/0.1 ha. The pattern of community evenness (not shown) matches that of the diversity.
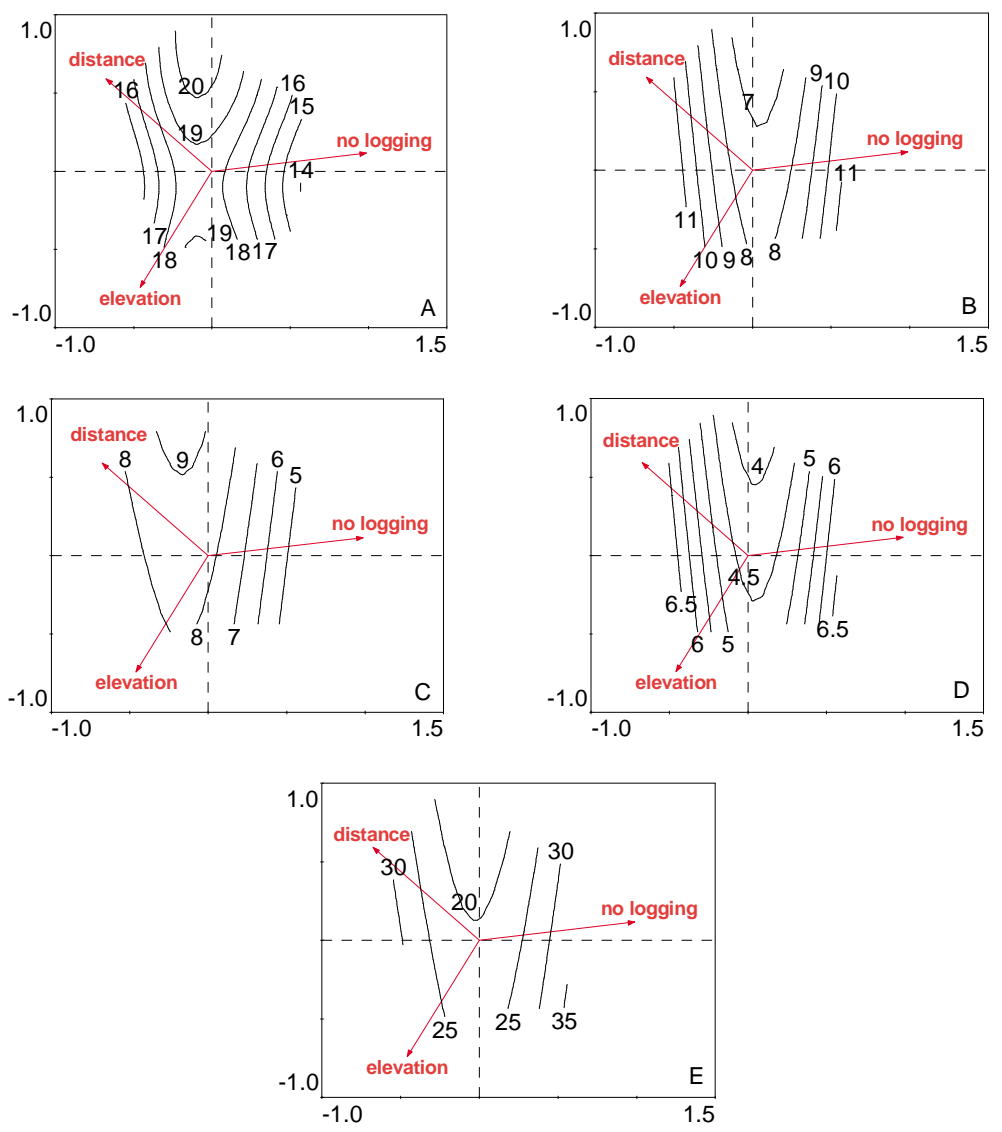

Figure 5. Response surfaces of some diversity and invasion variables. $\boldsymbol{A}=$ Hill's index of species diversity $\left(N_{2}\right) ; \boldsymbol{B}=$ alien species richness $/ 0.1$ ha; $\boldsymbol{C}=$ total species richness $/ 1 \mathrm{~m}^{2} ; \boldsymbol{D}=$ percent alien species of total flora; $\boldsymbol{E}=$ percent alien species in the plot $(0.1 \mathrm{ha})$. Contours denote predicted distribution of the chosen variables. Gradients are shown with arrows

Alien and invasive species richness/0.1 ha (Fig. 5B) has Gamma (log link) distribution with two peaks. One of the peaks is located in the low elevated, humid riparian habitats, distributed closely to the river channel. Alien species richness here 
gaining up to 12 species/0.1 ha. Another peak is centered far away from the river, in moderately elevated sites, with maximum of 17 alien species/ 0.1 ha. It is obvious that there is some discrepancy between distribution patterns of total richness and alien species richness, which contradicts the hypothesis that most diverse plant communities have greatest number of alien and invasive species (Stohlgren et al., 2003) (see also Table 1).

Distributional pattern of species richness $/ 1 \mathrm{~m}^{2}$ is shown on Fig. 5C. Its response surface is bimodal with modes, centered in the relatively xeric, low-elevated sites, with logging in the last 4-6 years. This distributional pattern to great extent overlaps with that of species richness $/ 0.1$ ha. Total species number $/ 1 \mathrm{~m}^{2}$ reaching maximum of 18 species.

Table 5. Variable response surface distribution and significance of the regression models. $* * * P<0.001 ; * * P<0.01 ; * P<0.05$

\begin{tabular}{l|l|c|c}
\hline \multicolumn{1}{c|}{ Variable } & Distribution & Model used & Model significance $(\boldsymbol{F})$ \\
\hline Species diversity $\left(N_{2}\right)$ & Gamma $(\log )$ & GAM & $5.36^{* *}$ \\
Alien species richness $/ 0.1$ ha & Gamma $(\log )$ & GAM & $4.23^{*}$ \\
Total species richness $1 \mathrm{~m}^{2}$ & Binomial & GAM & $11.71^{* * *}$ \\
Percent alien species of total flora & Gamma $(\log )$ & GAM & $4.22^{*}$ \\
Percent alien species/0.1 ha & Gaussian & GAM & $12.62^{* * *}$ \\
\hline
\end{tabular}

Percent of alien and invasive species of all species recorded (Fig. 5D) has Gamma (log link) response surface with two peaks, reaching maximum of $12.35 \%$. One of the peaks is located in most distant, xeric habitats, on approximate elevation of $110 \mathrm{~m}$. The other is centered in the opposite diametrical end of the graph, i.e. in the low-elevated, moist sites, distributed closely to the river bank. Percent of alien and invasive species of all recorded species in the 0.1 ha plot (Fig. 5E) has slightly different distributional pattern. It has one mode, located far away from the river, on relatively higher elevated sites $(47.73 \%)$, and another plateau-like mode, paralleling the river channel $(41.46 \%)$. It should be summarized that alien and invasive diversity patterns do not overlap with the distribution pattern of total diversity. The overall diversity at the different scales $(0.1$ ha and $1 \mathrm{~m}^{2}$ ) demonstrates similar distributional patterns in the environmental space, defined by the elevation, logging and moisture.

\section{Alien and invasive species distribution}

We analyzed distribution pattern of some of the most abundant alien and invasive species with GAM. Statistical parameters of the model are shown in Table 6. The greater number of aliens has Poisson distribution, which means that they have been displaced from their optima from the superior native species.

From Fig. 6 it can be seen that most alien species have their distributional peaks in the unlogged communities, distributed in the moister habitats, near to the river bank. For example, such species is Acer negundo, which abundance peaks in the most humid, low to middle elevated sites (approximately $107 \mathrm{~m}$ a.s.1.). Another such species is Amorpha fruticosa, which is most abundant in habitats, paralleling the river bank, at elevation from 104 to $112 \mathrm{~m}$. Other species demonstrate similar distributional patterns too. These are Morus alba, Chelidonium majus, Cucubalus baccifer and Urtica dioica. It is also obvious that there are species, having their distributional peaks in more xeric or distant from the river habitats. Such species, for example, is Conyza canadensis. 
Table 6. Species response surface distribution and significance of the regression models. $* * * P<0.001 ; * * P<0.01 ; * P<0.05 ;$ ns $=$ not significant

\begin{tabular}{l|c|c|c}
\hline Variable & Distribution & Model used & Model significance $(\boldsymbol{F})$ \\
\hline Acer negundo & Poisson & GAM & $82.70^{* * *}$ \\
Amorpha fruticosa & Poisson & GAM & $17.94^{* * * *}$ \\
Chelidonium majus & Poisson & GAM & $13.86^{* * *}$ \\
Cirsium arvense & Poisson & GAM & $12.79^{* * *}$ \\
Conyza canadensis & Binomial & GAM & $10.76^{* * *}$ \\
Cucubalus baccifer & Gamma $($ Log) & GAM & $7.60^{* *}$ \\
Melilotus albus & Gaussian & GAM & $3.16^{*}$ \\
Morus alba & Poisson & GAM & $14.91^{* * *}$ \\
Urtica dioica & Poisson & GAM & $29.85^{* * *}$ \\
\hline
\end{tabular}

Finally, there are species, which distribution is more complicated. They have two or more peaks in their predicted response surface. Such species is Lapsana communis (not shown). As a conclusion, it should be pointed out that most of the alien and invasive species, and especially the most abundant, are concentrated in the more humid, lowelevated riparian habitats, which have not been logged in the last ten or more years.
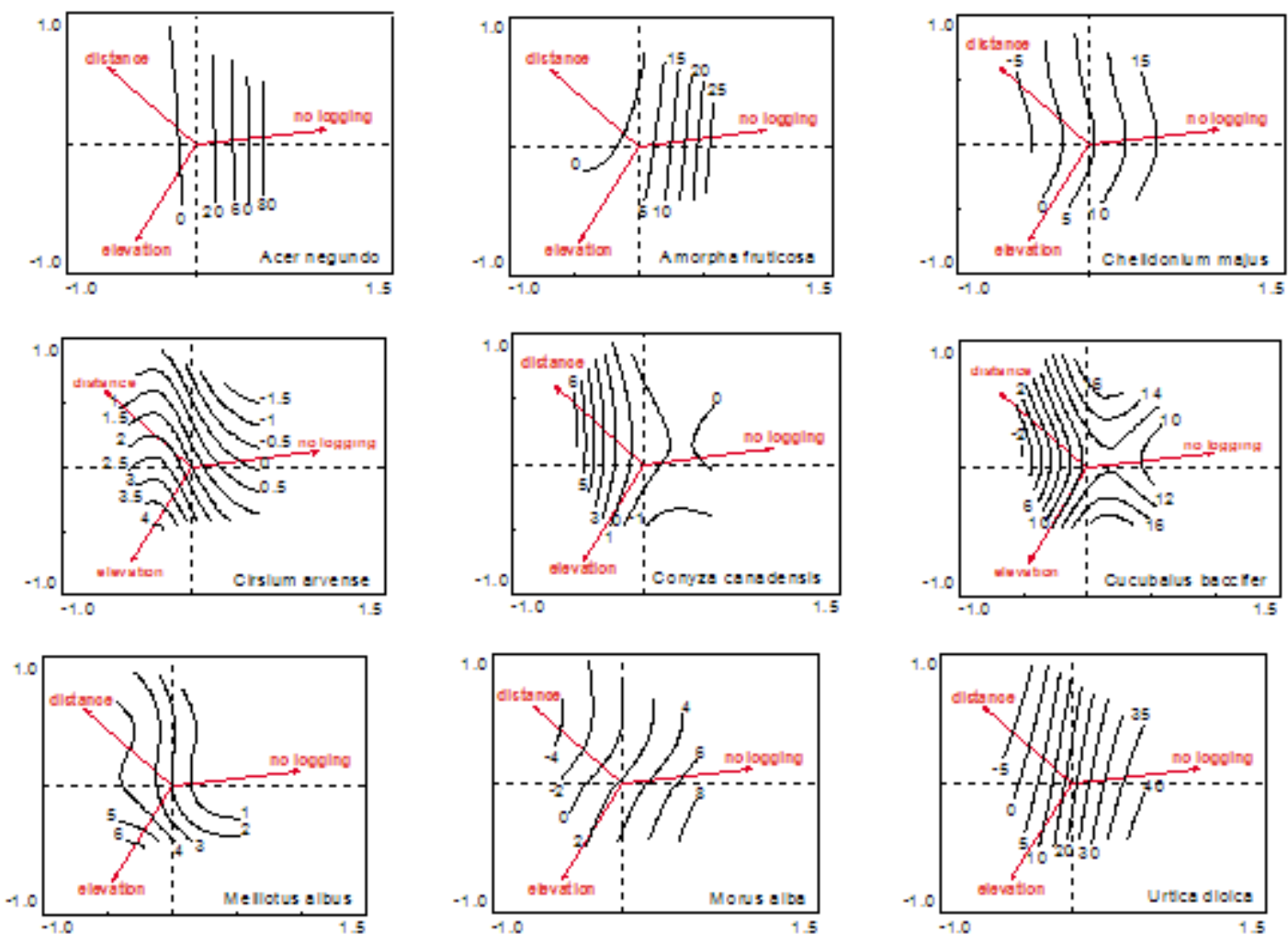

Figure 6. Response surfaces of the most abundant alien species with the principal environmental gradients. Contours denote predicted distribution (Importance Value) of main alien and invasive species 


\section{Discussion}

\section{Environmental and disturbance gradients}

The issue about the impact of invasive species on the invaded ecosystems is controversial. Tickner et al. (2001) maintained that the evidence of harmful ecological effects associated with invasions is seldom forthcoming. Usher (1988) claimed that presumed effects of invasive species are often shown through correlation with little conclusive evidence of cause and effect. Vitousek (1990) also acknowledged that much of the evidence of the effects of invasive plants was anecdotal. However, Richardson et al. (2007) comment that some plant species can alter vegetation composition and structure (termed 'transformers'), replacing indigenous vegetation over substantial areas and leading to changed ecosystem processes. They gave the example with the increased biomass of invasive Acacia mearnsii or Eucalyptus species in riparian zones, resulting in increased water use by the vegetation. Increased water use in turn led to altered hydrology of the catchment, causing stream reductions of up to $100 \%$ in afforested catchments in South Africa's grassland biome. Schnitzler et al. (2007) discussed that some invasive species in Europe (e.g. Amorpha fruticosa) take advantage of disturbance regimes of the riparian forests and integrate into the seed bank allowing rapid invasion of created gaps. They concluded that certain types of communities in temperate riparian forests are at potentially greater risk for exotic species, such that tend to be more open, including communities disturbed by timber harvesting. On the territory of the current study, there are places, where mixed riparian forest was cleared and replaced with poplar plantations. Once Amorpha fruticosa reaches such habitats, it creates dense, almost impenetrable shrub stands beneath the canopy, which brings great difficulties to further forestry activities. Furthermore, Amorpha fruticosa tends to occupy forest gaps in the riparian forest, i.e. microsites with concave surface and abundant moisture, remnants of old river beds. In these sites it creates dense populations, where other tree, shrub or even herb species are completely excluded. This species poses difficulties in forest road maintenance because it is able, by its sprouting growth, for a few years, especially if they are rainy years, to fully close human access through it. Finally, the dense Amorpha fruticosa populations, developing around water bodies, created naturally or artificially in proximity to the main river channel, are able to completely cut off the human access to them. We could add to the list of "transformers" Amorpha fruticosa because of its adverse effect mentioned here.

Other species (e.g. Acer negundo) are able to form dense stands in ruderal sites and deforested river banks, tendencies which appear less extensive in intact floodplains. According to Schnitzler (1995b), Acer negundo remained limited to a few pioneer communities within which its abundance was often low, except locally, attaining cover less than 5\% unless these forests became harvested. However, when violating the dynamic equilibrium of the habitats in question, this species could become highly invasive and impede natural forest regeneration. Walter et al. (2005) report that invasion of Acer negundo in stands of Salix alba changes succession patterns and species composition in floodplain forests of the lowlands of eastern Austria. This impeded the regeneration of native willow species by creating a second tree layer. Kurt and Callaway (2004) studied the effect of soil biota on Acer invasion in Europe and North America. They summarize that invasion of Acer negundo is enhanced by soil biota associated with dominant native species and that the soil biota effect becomes more 
inhibitory as the Acers establish. The authors also conclude that mutualists are relatively more beneficial to Acers in their nonnative ranges than in their native ranges because the invader has escaped from the negative effect of natural enemies that may attenuate the positive effect of mutualists. In our study, we found that Acer negundo dominates the river bank communities and continues to reproduce very successfully. These parts of the riparian habitat are among the most disturbed by the river water, but the canopy cover there was highest (see Table 1). This simply means that the light is not a limiting factor for Acer negundo and that it is well adapted to the flooding disturbance. The question whether it will continue to expand his local areal inward the forest is to be answered by further investigations.

Availability of water is considered to be a major limiting resource to riparian vegetation in arid and semiarid areas, especially for woody riparian species that are rooted in the water table (Richardson et al., 2007). Naiman and Décamps (1997) commented that in riparian habitats often exists spatial zonation as a gradient perpendicular to the river bed. It is complex gradient made by vegetation responses to local variations in topography and flooding regime. Nilsson and Svedmark (2002) notice that in many parts of the world riparian plant communities are arranged along the local elevation gradient into more or less distinct zones, from a forest margin, succeeded by shrub communities, and herbaceous plants from highest to lowest positions along this gradient. The distribution of floodplain vegetation is primarily determined by gradients of available moisture and oxygen, which gradients are influenced by (1) hydrological and sediment transport regimes of the river, (2) geomorphologic history of floodplain construction, which controls floodplain micro topography and (3) sedimentary structure (Tickner et al., 2001). Turner et al. (2004) found that indicators of flooding regime (relative elevation and distance from main channel) were consistently important in predicting occurrence, community composition and abundance of trees. They concluded that physiography and indicators of flood regime are particularly useful for explaining floodplain forest structure and composition in floodplains (Turner et al. 2004). Ward (1998) also commented the spatial broad-scale vegetation zonation, according to elevation gradient of the river floodplain, but the author noticed as well that at finer scale species segregate according to microsite. Ward et al. (2002) discussed the zonation phenomenon and added that these riparian zones reflect the speciesspecific reaction to soil moisture, sediment deposition, the frequency and duration of inundation, and the erosive action of flooding. Our ordination and regression analyses confirmed the existence of moisture gradient. Most invasive species prefer and occupy habitats in its humid end. In our case, this complex gradient is a reflection, on the first place, of the proximity to the river and the lower elevation (water table closer to the soil surface). We find support to this hypothesis in the negative correlation of most alien and invasive species with the distance gradient, given that most of them are distributed by the river water. Furthermore, the most abundant species, especially Amorpha fruticosa and Acer negundo, are also negatively correlated with the elevation. Predicted spatial distribution, revealed by the regression analysis, shows their preferences of more humid, and closer to the river, habitats. Some vegetation variables showed statistically significant differences among the described plant communities. These differences express the variable environmental conditions in the adjacent segments of the moisture gradient.

Burton et al. (2005) found significant decrease in basal area and forest cover along the urban gradient. They ascribed this phenomenon to decreasing forest productivity 
and history of timber harvesting. They also speculated that decreasing of basal area and diversity in the regeneration layer along the urban gradient may be related to the intensity of anthropogenic disturbance, such as the reduction of forest cover and increased sources of non-native species. In our study, supporting evidences for the existence and influence of the logging gradient on the distribution and abundance of the main alien and invasive species are obscure. This holds despite the fact that there is significant difference between the plant communities, relative to logging gradient. Practically, formal logging activities in the closest to the river riparian habitats in the last 10 years were lacking. But there were other disturbance events (periodic floods, illegal logging), which may have blurred the influence of the logging activities. Some of the most abundant species (e.g. Amorpha fruticosa, Acer negundo, Morus alba, Urtica dioica) were positively correlated with the unlogged habitats, but there were also many species (e.g. Gallega officinalis, Sonchus arvensis, Melilotus albus, Lapsana communis) that showed the opposite trend. Moreover, GAM showed that the distribution patterns of some of the later species are too complicated, i.e. they have complex response surface with more than one mode, centered in different parts of the environmental space. Due to these reasons, we consider the logging gradient as an unreliable predictor of the alien and invasive species distribution on the territory of the current study at the 0.1 ha scale.

The importance of study scale is obvious. We supported the Reed et al.'s (1993) hypothesis that the correlation between vegetation and environment should increase with increasing plot size. According to the authors this could be consequence of sampling error because only few plants fit in the small subplot due to chance alone, introducing great heterogeneity in the data set. This is reflected in the great amount of unexplained variation and extremely long gradients (see Table 3) in our DCA analysis. We agree that for detection of subtle vegetation pattern, larger samples enlisting many species are needed (Reed et al., 1993). The assumption that association between vegetation and environment are consistent across a wide range of spatial scales is supported in this study. Contrary to some previous studies (Reed et al. 1993; Palmer 1990) we found that the same environmental gradients play significant role at the different spatial scales, but with different strength. Finally, our results, with some exceptions for the alien species, showed that sampling over larger area leads to higher correlations between vegetation and environment. As Reed et al. (1993) discuss, larger samples are likely to capture greater portion of the variation in vegetation and environment, but we also add, with greater homogeneity in the data set, which probably yields the higher correlations. Therefore, when analyzing vegetation-environment relationships, we recommend sampling of larger areas, when possible.

\section{Diversity}

Negative impact on native or exotic species diversity of anthropogenic or natural processes has been documented in many studies. Burton et al. (2005) reported that the proportion of non-native species in the canopy and regeneration layer decreased and diversity of the regeneration layer increased along an urban gradient of the riparian forest studied. They assigned this pattern to the anthropogenic disturbance that may subdue the ability of diverse communities to resist non-native plant invasions. Obedzinski et al. (2001) discussed that logging leads to compacted and disturbed soil, which increases erosion, reduces growth, and further stresses residual plants and that vegetation removal also can alter temperature, species composition, and structural diversity of riparian forest. They also noted that shifts toward exotic woody plants could 
significantly influence wildlife habitat (e.g. reductions in diversity, faunal-plant assemblages, and uniqueness) of riparian systems. Anthropogenic impacts such as flow regulation, channelization, and bank stabilization eliminate upstream-downstream linkages and isolate river channels from riparian/floodplain systems and contiguous groundwater aquifers. These alterations interfere with successional trajectories, habitat diversification, migratory pathways and other processes, thereby reducing biodiversity (Ward, 1998). Also, fluvial action (erosion, transport, deposition) is the predominant agent of landscape evolution and also constitutes the natural disturbance regime primarily responsible for sustaining a high level of landscape diversity in river corridors (Ward et al., 2002).

According to Nilsson and Svedmark (2002) there are several reasons for the high species diversity of riparian plant communities: 1) floods create spatial and temporal heterogeneity, 2) disturbances by the natural floods create mosaic of patches with different disturbance history and successional stages, 3) flowing across biomes, rivers encounter large proportion of regional flora, 4) excellent plant ability to migrate along riparian corridors. Natural flood regimes help to maintain high species diversity not only by creating a diversity of temporal regeneration niches but also by creating micro habitats that vary spatially in depth to the water table, light availability, and soil properties (Stromberg, 2001). Many studies (Tabacchi et al., 1998; Schnitzler et al., 2007) of native and exotic plant species richness of riparian vegetation support Intermediate Disturbance Hypothesis (IDH) (Connell, 1978; Huston, 1979). Our results show similar diversity patterns. The richest on species plant communities were situated at intermediate distance to the river, where hydrological disturbance levels were moderate. These plant communities were also more diverse and with highest evenness. However, when diversity was divided into functional types, different patterns emerged. Richest on tree and shrub species communities occupied closest to the river habitats, where invasive tree and shrub (Acer negundo, Amorpha fruticosa) species dominated. Perennials were most numerous in more xeric and distant from the river habitats. This pattern was evident for the annual and biennial functional types too.

Décamps et al. (2004) share that along transects perpendicular to the river banks, plant species diversity follows the pattern predicted by IDH. They discuss results of Gregory et al. (1991), where species diversity/1 $\mathrm{m}^{2}$ was low on highly disturbed depositional bars near the river, highest on active channel shelves, moderately disturbed by floods, and decreasing in the floodplain terrace and upland communities, where floods are progressively less frequent. Our results do not contradict this pattern. We found that the most diverse plant communities at $1 \mathrm{~m}^{2}$ scale were distributed in relatively xeric, low elevated, and on intermediate distance from the river bed, habitats. Such trend can be explained with herb species number, which contributes most to the species richness at that scale. They adapt more hardly and rarely survive the frequent floods, happening periodically close to the river bed. Furthermore, declines in species diversity can occur if flood disturbance becomes infrequent or if the temporal and spatial diversity of flood disturbance declines (Stromberg, 2001).

Stohlgren et al. (1999) analyzed the correlation between high native and invasive species richness and offered the following generalizations: 1) both native and exotic plant species respond favorably to fertile areas and available resources, 2) the attribute of high species richness does not ensure complete use of all available resources, stability, or resistance to invasion and 3) many other factors are likely far more important indicators of invasion than the attribute of species richness. Analyzing 
riparian and upland forests, Stohlgren et al. (1998) found significantly greater foliar cover of native species at $1 \mathrm{~m}^{2}$ scale, compared to upland sites, but there were no consistent pattern of native and exotic species richness. We also found significantly greater tree layer cover and species richness of all species at $1 \mathrm{~m}^{2}$ of the moist riparian habitats, compared to distant xeric habitats. They have found significantly greater mean exotic species richness at 0.1 ha in riparian zones, compared to upland sites. On the contrary, we have not found significant difference in the species richness at this scale, but have found significantly greater importance value of all alien and invasive species in moist riparian habitats. This trend is supported by the results of Barton et al. (2004). They found that invasive abundance and diversity were highest in riparian areas of rural New England town, probably due to relatively high levels of propagule pressure. Uowolo et al. (2005) found higher species richness/0.1 ha on unregulated river terrace in riparian forest of northwest Colorado. They also found strong positive correlation between native and exotic species richness/0.1 ha. Other studies found positive correlation in that context too (Stohlgren et al., 1998; Allen et al., 2009). Our results showed similar trend in alien and native species richness with positive, but weak correlation $\left(R_{s}=0.37 ; P=0.05\right)$. When analyzed with GAM regression, complex pattern of species richness response surfaces emerged. There were obvious discrepancies between the distribution of alien and native species. Stohlgren et al. (1998) concluded that richest on species habitats and productive riparian zones are particularly invasible in grassland ecosystems, and that riparian zones may act as havens, corridors, and sources of exotic plant invasions for upland sites. We can ascribe the same conclusion about the riparian ecosystem studied.

Acknowledgements. We are very thankful to Suzana Stankulovska and Ivan Kafedjiev for their indispensable help in the field work. This study was funded by grant No 48/1304 of the Scientific Fund at University of Forestry, Sofia, Bulgaria.

\section{REFERENCES}

[1] Allen, J., Brown, C., Stohlgren, T. (2009): Non-native plant invasions of United States National Parks. - Biological Invasions 11: 2195-2207.

[2] Barton, A., Brewster, L., Cox, A., Prentiss, N. (2004): Non-indigenous woody invasive plants in a rural New England town. - Biological Invasions 6: 205-211.

[3] Burton, M., Samuelson, L., Pan, S. (2005): Riparian woody plant diversity and forest structure along an urban-rural gradient. - Urban Ecosystems 8: 93-106.

[4] Carol, J., Benejam, L., Alcaraz, C., Vila-Gispert, A., Zamora, L., Navarro, E., Armengol, J., Garc1'a-Berthou, E. (2006): The effects of limnological features on fish assemblages of 14 Spanish reservoirs. - Ecology of Freshwater Fish 15: 66-77.

[5] Connell, J. (1978): Diversity in tropical rain forest and coral reefs. - Science 199: 13021310.

[6] Decamps, H., Pinay, G., Naiman, R., Petts, G., Mcclain, M., Hillbricht-Ilkowska, A., Hanley, T., Holmes, R., Quinn, J., Gibert, J, Planty-Tabacchi, A., Schiemer, F., Tabacchi, E., Zalewski, M. (2004): Riparian zones: where biogeochemistry meets biodiversity in management practice. - Polish Journal of Ecology 52: 3-18.

[7] Gregory, S., Swanson, F., McKee, W., Cummins, K. (1991): An ecosystem perspective of riparian zones. - BioScience 41: 540-551. 
[8] Hill, M., Šmilauer, P. (2005): TWINSPAN for Windows version 2.3. - Centre for Ecology and Hydrology \& University of South Bohemia, Huntingdon \& Ceske Budejovice.

[9] Hill, M. (1979): TWINSPAN - A FORTRAN program for arranging multivariate data in an ordered two-way table by classification of individuals and attributes. - Cornell University Ithaca, NY, $90 \mathrm{pp}$.

[10] Hill, M.O. (1973): Diversity and Evenness: A Unifying Notation and Its Consequences. Ecology 54: 427-432.

[11] Hill, M., Gauch, H. (1980): Detrended correspondence analysis: an improved ordination technique. - Vegetatio 42: 47-58.

[12] Huston, M. (1979): A general hypothesis of species diversity. - The American Naturalist 113: 81-101.

[13] Krebs, C. (1999): Ecological Methodology. 2nd ed. - Benjamin Cummings, Menlo Park, California. 620 pp.

[14] Kurt, R., Callaway, R. (2004): Soil biota facilitate exotic Acer invasions in Europe and North America. - Ecological Applications 14: 1737-1745.

[15] Lepš, J., Šmilauer, P. (1999): Multivariate Analysis of Ecological Data. Faculty of Biological Sciences. - University of South Bohemia Ceské Budejovice.

[16] Naiman, R.J., Décamps, H. (1997): The ecology of interfaces: Riparian Zones. - Annu. Rev. Ecol. Syst. 28: 621-58.

[17] Nilsson, C., Berggren, K. (2000): Alterations of Riparian Ecosystems Caused by River Regulation. - Bioscience 50(9).

[18] Nilsson, C., Svedmark, M. (2002): Basic Principles and Ecological Consequences of Changing Water Regimes: Riparian Plant Communities. - Environmental Management 30: 468-480.

[19] Obedzinski, R., Shaw, C., Neary, D. (2001): Declining Woody Vegetation in Riparian Ecosystems of the Western United States. - West. J. Appl. For. 16: 169-181.

[20] Palmer, M. (1993): Putting Things in Even Better Order: The Advantages of Canonical Correspondence Analysis. - Ecology 74: 2215-2230.

[21] Palmer, M. (1990): Spatial scale and patterns of speciesenvironment relationships in hardwood forests of the North Carolina piedmont. - Coenoses 5: 79-87.

[22] Peet, R. (1974): The measurement of species diversity. - Annu. Rev. Ecol. Syst. 5: 285307.

[23] Planty-Tabacchi, A.M., Tabacchi, E., Naiman, R.J., Deferrari, C., Décamps, H. (1996): Invasibility of species rich communities in riparian zones. - Conservation Biology 10: 598-607.

[24] Reed, R., Peet, R., Palmer, M., White, P. (1993): Scale dependence of vegetationenvironment correlations: A case study of a North Carolina piedmont woodland. Journal of Vegetation Science 4: 329-340.

[25] Richardson, D.M., Holmes, P.M., Esler, K.J., Galatowitsch, S.M., Stromberg, J.C., Kirkman, S.P., Pysek, P., Hobbs, R.J. (2007): Riparian vegetation: degradation, alien plant invasions, and restoration prospects. - Diversity and Distributions 13: 126-139.

[26] Richardson, D.M., Pysek, P., Rejmánek, M., Barbour, M.G., Panetta, F.D., West, C.J. (2000): Naturalization and invasion of alien plants - concepts and definitions. - Diversity and Distributions 6: 93-107.

[27] Schnitzler, A., Hale, B., Alsum, E. (2007): Examining native and exotic species diversity in European riparian forests. - Biological Conservation 138: 146-156.

[28] Šmilauer, P. (1999-2003): CanoDraw for Windows, version 4.1. - Glenn RandersPehrson.

[29] StatSoft Inc. (2007) STATISTICA (data analysis software system), version 8.0. www.statsoft.com.

[30] Stohlgren, T.J., Barnett ,D.T., Kartesz, J.T. (2003): The rich get richer: patterns of plant invasions in the United States. - Frontiers in Ecology and the Environment 1: 11-14. 
[31] Stohlgren, T.J., Bull, K., Otsuki, Y., Villa, C., Lee, M. (1998): Riparian zones as havens for exotic plant species in the central grasslands. - Plant Ecology 138: 113-125.

[32] Stromberg, J. (2001): Restoration of riparian vegetation in the south-western United States: importance of flow regimes and fluvial dynamism. - Journal of Arid Environments 49: 17-34.

[33] Systat Software Inc. (2008) SigmaPlot for Windows, version 11.0. www.sigmaplot.com.

[34] Tabacchi, E., Correll, D., Hauer, R., Pinay, G., Planty-Tabacchi, A., Wissmar, R. (1998): Development, maintenance and role of riparian vegetation in the river landscape. Freshwater Biology 40: 497-516.

[35] ter Braak, C.J.F., Šmilauer, P. (1997-2003): CANOCO for Windows, version 4.51. Biometrics, Plant Research International, Wageningen, The Netherlands.

[36] ter Braak, C.J.F. (1986): Canonical Correspondence Analysis: A New Eigenvector Technique for Multivariate Direct Gradient Analysis. - Ecology 67: 1167-1179.

[37] Thomas, Y., Mitchell, N. (1991): Generalized additive models in plant ecology. - Journal of Vegetation Science 2: 587-602.

[38] Thuiller, W., Araujo, M., Lavorel, S. (2003): Generalized models vs. classification tree analysis: Predicting spatial distributions of plant species at different scales. - Journal of Vegetation Science 14: 669-680.

[39] Tickner, D.P., Angold, P.G., Gurnell, A.M., Mountford, J.O. (2001): Riparian plant invasions: hydrogeomorphological control and ecological impacts. - Progress in Physical Geography 25: 22-52.

[40] Turner, M., Gergel, S., Dixon, M., Miller, J. (2004): Distribution and abundance of trees in floodplain forests of the Wisconsin River: Environmental influences at different scales. - Journal of Vegetation Science 15: 729-738.

[41] Usher, M. (1988): Biological invasions of nature reserves: a search for generalizations. Biological conservation 44: 119-135.

[42] Walter, J., Essl, F., Englisch, T., Kiehn, M. (2005): Neophytes in Austria: Habitat preferences and ecological effects. - In: Nentwig et al. (Eds.): Biological Invasions From Ecology to Control. - Neobiota 6: 13-25.

[43] Ward, J. (1998): Riverine landscapes: biodiversity patterns, disturbance regimes and aquatic conservation. - Biological Conservation 83: 269-278.

[44] Ward, J., Tockner, K., Arscott, D., Claret, C. (2002): Riverine landscape diversity. Freshwater Biology 47: 517-539.

[45] Whittaker, R. (1956): Vegetation of the Great Smoky Mountains. - Ecological Monographs 26: 1-80. 